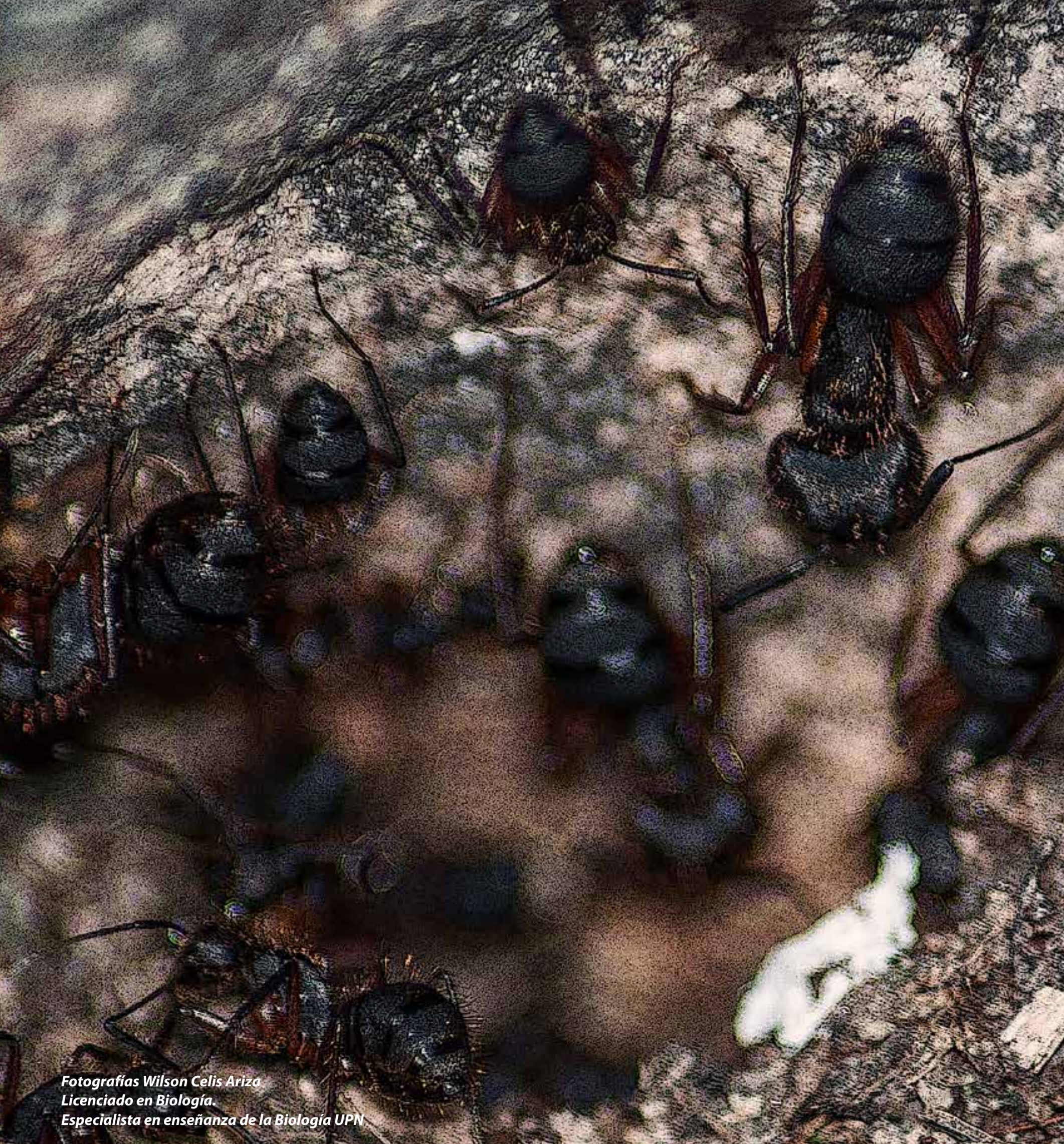

Especialista en enseñanza dela Biologra UPL (1)

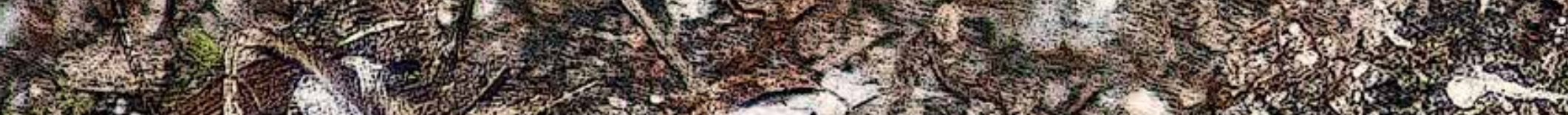

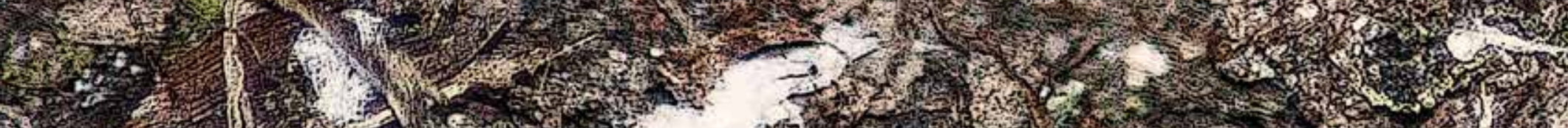

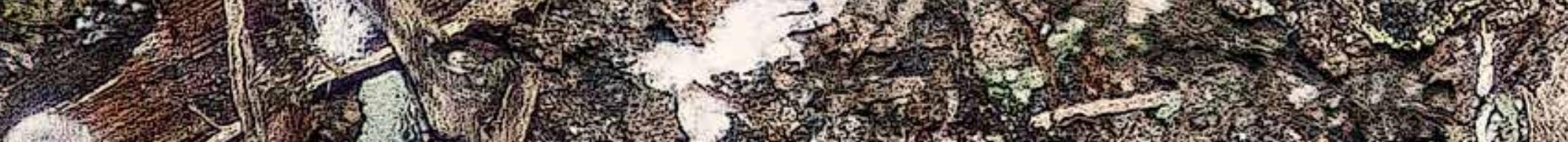




\title{
LAS COMPETENCIAS BÁSICAS EN LA ENSEÑANZA DE LA BIOLOGÍA EN EDUCACIÓN SECUNDARIA'
}

\section{CORE COMPETENCES IN THE TEACHING OF BIOLOGY IN SECONDARY EDUCATION}

Fecha de recepción: 09 de septiembre de 2014

Fecha de aprobación: 24 de noviembre de 2014

\author{
Antonio Joaquín Franco-Mariscal $l^{(*)}\left({ }^{\star *}\right)$ \\ Enrique España-Ramos ${ }^{(* *)}$ \\ Ángel Blanco-López ${ }^{(* *)}$
}

\section{Resumen}

Este artículo presenta una unidad didáctica en torno al problema de la salud e higiene bucodental, diseñada para fomentar el desarrollo de las competencias básicas en estudiantes españoles de secundaria de 15-16 años, prestando especial atención en la competencia científica. Los resultados de la puesta en práctica y evaluación de dicha unidad durante tres cursos escolares, ponen de manifiesto que la mayoría de los estudiantes alcanzan los objetivos previstos y muestran avances en el desarrollo de sus competencias básicas, aumentando su motivación e interés por la ciencia.

\section{Palabras clave}

Competencias básicas, competencia científica, enseñanza de la biología, unidad didáctica, salud bucal

\section{Abstract}

A teaching unit about oral and dental health and hygiene, designed to encourage key competences in high school Spanish students (aged 15-16), with particular emphasis on scientific competence is presented in this paper. The results of the implementation and assessment of the unit for three school years show that the most of the students reaches the expected objectives improving their key competences. An increase in students' motivation and interest in science is observed too.

\section{Keywords}

key competences, scientific competence, teaching biology, teaching unit, oral health

\footnotetext{
1 Este artículo forma parte del proyecto de I+D+i «Diseño y evaluación de un modelo para el fomento de la competencia científica en la educación obligatoria (10-16 años)» (EDU2009-07173) financiado por el Ministerio de Ciencia e Innovación en la convocatoria de 2009.

(*) I.E.S. Juan Ramón Jiménez (Málaga, España). antoniojoaquin.franco@uma.es
}

(**) Universidad de Málaga (Málaga, España).enrienri@uma.es; ablancol@uma.es 


\section{Introducción}

Desde hace algunos años el marco de las competencias constituye un paradigma emergente a nivel internacional que está siendo usado para alumbrar cambios en los distintos niveles educativos. Los currículos actuales de la Educación Obligatoria en España plantean una orientación de la enseñanza hacia el desarrollo de competencias básicas, entendidas como un conjunto de habilidades interiorizadas por el estudiante que le permiten saber aplicar los conocimientos adquiridos y desenvolverse en diferentes contextos de la vida académica, personal y, en última instancia, laboral (Ministerio de Educación y Ciencia, 2007).

De acuerdo con el currículo español, las competencias básicas son ocho:

(a) Competencia en comunicación lingüística $(\mathrm{CL})$, referida a la utilización del lenguaje como instrumento de comunicación oral y escrita, tanto en lengua española como en lengua extranjera.

(b) Competencia de razonamiento matemático (CM), entendida como la habilidad para utilizar números y operaciones básicas, los símbolos y las formas de expresión del razonamiento matemático para producir e interpretar informaciones y para resolver problemas relacionados con la vida diaria y el mundo laboral.

(c) Competencia en el conocimiento y la interacción con el mundo físico y natural (en adelante, competencia científica, CC). Se entiende como la habilidad para interactuar con el mundo físico, tanto en sus aspectos naturales como en los generados por la acción humana y para desenvolverse adecuadamente (con autonomía e iniciativa personal) en ámbitos de la vida y del conocimiento muy diversos (salud, actividad productiva, consumo, ciencia, procesos tecnológicos, etc.).

(d) Competencia digitaly tratamiento de la información (TICD), entendida como la habilidad para buscar, obtener, procesar y comunicar la información y transformarla en conocimiento, incluyendo la utilización de las tecnologías de la información y la comunicación como un elemento esencial para informarse y comunicarse.

(e) Competencia social y ciudadana (CSC), entendida como aquella que permite vivir en sociedad, comprender la realidad social del mundo en que se vive y ejercer la ciudadanía democrática.

(f) Competencia cultural y artística (CCA), que supone apreciar, comprender y valorar críticamente diferentes manifestaciones culturales y artísticas, utilizarlas como fuente de disfrute y enriquecimiento personal y considerarlas como parte del patrimonio cultural de los pueblos. (g) Competencia aprender a aprender (AA), para seguir aprendiendo de forma autónoma a lo largo de la vida.

(h) Competencia para la autonomía e iniciativa personal (AIP), que incluye la posibilidad de optar con criterio propio y espíritu crítico, y llevar a cabo las iniciativas necesarias para desarrollar la opción elegida y hacerse responsable de ella. Incluye la capacidad emprendedora para idear, planificar, desarrollar y evaluar un proyecto.

De todas ellas, la competencia más relacionada con la enseñanza de la biología es la competencia científica, lo que no significa que desde esta área no deban atenderse el resto de competencias, sino todo lo contrario el profesorado debe diseñar unidades didácticas que ofrezcan diferentes posibilidades para que el alumnado pueda desarrollar todas las competencias básicas del currículo.

Con estas premisas como punto de partida, desde hace varios años y dentro de un proyecto de investigación, desarrollo e innovación desarrollado en la Universidad de Málaga (España) (Blanco, España y González, 2010; Blanco, España y Rodríguez, 2012),profesores de ciencias de secundaria trabajan conjuntamente con profesores de didáctica de las ciencias de la universidad en el diseño, la implementación y la evaluación de diferentes unidades didácticas centradas en las competencias básicas en general, y la competencia científica en particular.

\section{Competencias básicas en una unidad didáctica de biología}

Desarrollar competencias básicas en el alumnado supone alejarnos de una metodología tradicional de enseñanza. De este modo, en la unidad didáctica sobre salud bucal que aquí se presenta, la primera sesión comienza mostrando en la pizarra digital dos imágenes de las sonrisas de dos personas en las que se aprecian sus dentaduras, una limpia y otra con caries, y con una pregunta que lanza el profesor a sus estudiantes: ¿con cuál de estas dos personas saldrías a dar un paseo? Se trata de una actividad que pretende motivar a los estudiantes y atraer su atención hacia el tema de la caries bucal, y sin duda, lo hace abriendo un debate entre los estudiantes desde la primera toma de contacto con la unidad.

En nuestra opinión, trabajar en el aula de secundaria el desarrollo de competencias básicas no es tan difícil. Una forma de hacerlo, implica tener una visión amplia de los contenidos que propone el currículo (Ministerio de Educación y Ciencia, 2007) y relacionarlos entre sí en torno a problemas y/o situaciones relevantes de la vida diaria, independientemente de que aquellos aparezcan en el 
currículo en núcleos de contenidos o materias diferentes, pero que se hacen necesarios utilizarlos para que la unidad didáctica tenga sentido en sí misma.

De este modo, el enfoque de unidades didácticas por el que hemos optado en el citado proyecto se enmarca dentro de la enseñanza de las ciencias basada en el contexto y problemas cotidianos, ya que existe una vinculación directa entre las competencias y la vida diaria (Perrenoud, 2012). En este sentido, el programa PISA (OCDE, 2006) utiliza para la evaluación contextos y situaciones de la vida diaria: la salud, los recursos naturales, el medio ambiente, los riesgos o la frontera de la ciencia y la tecnología. Estos contextos pueden ser adecuados para diseñar unidades didácticas que permitan desarrollar competencias en nuestros alumnos.

Desde nuestro punto de vista, un problema puede ser utilizado como contexto adecuado para trabajar las competencias básicas en el aula, si cumple los siguientes requisitos: 1) ser relevante en la vida diaria; 2) formar parte del entorno cultural del estudiante; 3) captar su interés; y 4) permitir su tratamiento didáctico en el aula (España, Blanco y Rueda, 2012).

En esta línea de trabajo, este artículo presenta cómo se pueden introducir las distintas competencias básicas en el diseño de una unidad didáctica para la enseñanza de la biología tomando como ejemplo una de las diseñadas en el proyecto, concretamente, una unidad sobre salud e higiene bucodental destinada a estudiantes de 15-16 años. Este contexto se eligió por varias razones, entre las que destacan el elevado porcentaje de alumnos españoles de estas edades que poseen caries (un 60\%) (Bravo et al., 2006) y la importancia de una correcta higiene dental en la calidad de vida y bienestar psicológico de las personas (Ramos, 2010).

Aunque la unidad gira en torno a contenidos científicos relacionados con la salud bucal, y potencia en todas sus tareas el desarrollo de la competencia científica (CC) como se ha indicado por ser la más cercana a la enseñanza de la biología-, ofrece también la oportunidad de que los alumnos ejerciten y desarrollen aspectos importantes del resto de competencias básicas. Así, como se mostrará más adelante, algunas actividades demandan la utilización de cálculos numéricos para la comprensión de algunos aspectos del problema(competencia matemática, $\mathrm{CM}$ ), mientras que otras requieren el uso de Internet para la búsqueda de información (tratamiento de la información y competencia digital, TICD). Este aspecto toma especial relevancia en la unidad, y se convierte en uno de sus objetivos, ya que la cantidad inabarcable de información disponible en Internet hace que el estudiante deba aprender a gestionar la información, saber valorar su calidad y tener un espíritu crítico ante ella, aspectos fundamentales de la competencia científica deseable para la ciudadanía (Blanco, España, González y Franco, 2015). El alumno debe comprender, resumir y comunicar a sus compañeros toda esta información tanto de forma oral como escrita (competencia lingüística, CL), lo que conduce a elaborar conocimientos (aprender a aprender, AA), y en algunos casos, a tomar decisiones en el diseño de experimentos (autonomía e iniciativa personal, AIP) o en situaciones con implicaciones sociales (competencia social y ciudadana, CSC) como puede ser el consumo de drogas. Finalmente, la competencia cultural y artística (CCA) se desarrolla con la elaboración de un tríptico informativo en el que se debe resumir de forma divulgativa todo lo aprendido en la unidad.

\section{¿Qué objetivos se pretenden?}

En la Tabla 1 se concretan los objetivos didácticos y las competencias básicas abordadas. En este sentido, no es conveniente plantearse un gran número de objetivos, sino solamente los que requiera el tratamiento de la salud e higiene bucodental. Por tanto, la unidad didáctica resultante tiene un carácter multidisciplinar ya que aborda otros contenidos no específicos de biología, lo que implica que se podría trabajar también desde otras materias o conjuntamente.

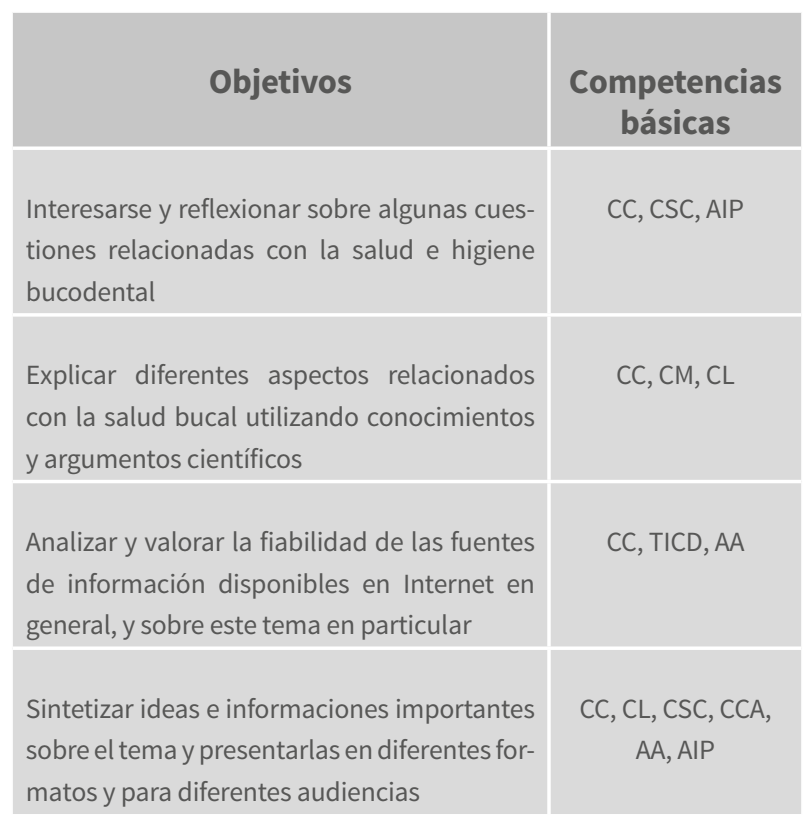

Tabla 1. Objetivos didácticos y competencias básicas 


\section{¿Para qué contenidos?}

Como se ha indicado, el desarrollo del problema a tratar va determinando los contenidos a incluir. Esta unidad se organizó en cuatro grandes bloques de contenidos, cuyos títulos y secuencia temporal se muestran en la Figura 1.

Bloques de contenidos

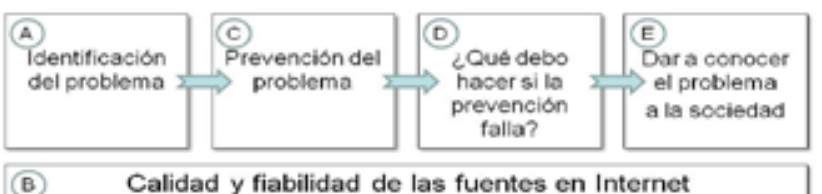

(B)

Calidad y fiabilidad de las fuentes en Internet

\section{La secuenciadidáctica}

La unidad se estructura en cuatro fases (orientación y explicitación de ideas previas, desarrollo y construcción de conocimientos, aplicación de conocimientos, síntesis, recapitulación y evaluación) de acuerdo con un enfoque constructivista del desarrollo del currículo (Pro y Saura, 2007). En la Tabla 2 se presenta la secuencia de actividades mostrando ejemplos de tareas que se realizan en cada una de las fases y bloques de contenidos. Se describen de forma resumida cada una de las tareas presentadas indicando, en cursiva, su intencionalidad didáctica. También se muestran las competencias básicas con las que cada tarea tiene una relación más directa.

Figura 1. Bloques de contenidos en los que se organiza la unidad didáctica

La unidad incluye además un quinto bloque transversal (B), que se trabaja de forma global a lo largo de la misma, en torno a la calidad y fiabilidad de las fuentes de información, ya citada.

Cada bloque incluye una serie de contenidos conceptuales, procedimentales y actitudinales. Así, el bloque A aborda los alimentos azucarados, las bacterias de la boca, las piezas dentales y las reacciones químicas, mientras que el bloque $B$ trabaja la fiabilidad de las fuentes de Internet, centrándose especialmente en la relación entre drogas y caries. Por su parte, el bloque $\mathrm{C}$ centra la prevención del problema en tres líneas: revisiones periódicas al dentista (radiografías dentales), cepillado (composición química de dentífricos y enjuagues bucales) y el consumo adecuado de alimentos azucarados. El bloque D trata los empastes, el uso de mercurio en los mismos y su relación con la salud. Por último, el bloque E sirve para aplicar los contenidos estudiados en los bloques anteriores. El lector puede deducir el tipo de contenido implicado en cada caso a través de la descripción que de cada una de las tareas de la unidad se realiza seguidamente en la Tabla 2. 


\section{Fase de orientación y explicitación de ideas previas}

\section{Bloque A: Identificación del problema}

\section{Acercamiento al problema de la caries dental}

Justificar razonadamente con qué persona se relacionaría el estudiante a partir del estado de su boca presentado a través de una fotografía,en la que aparece una persona con los dientes sucios y con caries, y otra con los dientes totalmente limpios y aseados.

Esta primera actividad tiene como objetivo situar a los alumnos en el contexto y atraer su atención hacia el problema a tratar

\section{Bloque B: Buscando información en Internet para entender el problema}

2.

\section{Calidad y fiabilidad de las fuentes de Internet}

Comprender y resumir adecuadamente la información de un artículo (Fornás, 2003) sobre la calidad y fiabilidad de las fuentes de Internet, del que deben extraer una serie de indicadores para conocer si el contenido de una web es fiable.

Se pretende que los alumnos conozcan los criterios que se pueden utilizar para analizar la fiabilidad y credibilidad de una fuente en Internet (véase la sección de evaluación de competencias).

\section{Fase de desarrollo y construcción de conocimientos del tema}

\section{Bloque A: Identificación del problema (Continuación)}

3. ¿Qué interviene en la aparición de la caries?

Predecir qué le ocurre a un diente en contacto con azúcar y comprobar las hipótesis planteadas diseñando y realizando una experiencia de laboratorio.

Se pretende que a través de la experimentación el estudiante sea capaz de reconocer el azúcar y la presencia de la placa bacteriana en la boca como los principales factores responsables de la caries.

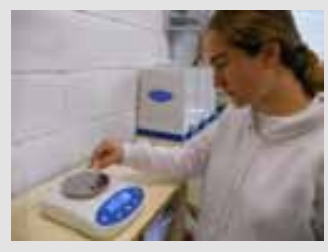

4. ¿Cómo se produce la caries?

Buscar información en Internet para conocer la estructura de un diente, e identificar y nombrar cada una de sus partes en un dibujo. Explicar a partir del dibujo cómo se produce la caries.

El estudiante debe identificar las partes de un diente como base para explicar cómo tiene lugar la evolución de una caries desde el esmalte hasta el nervio.

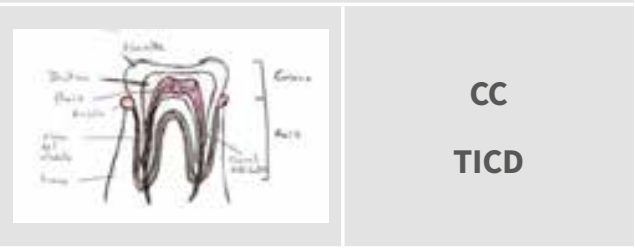

5.

¿Cómo entienden los químicos la caries?

Interpretar la fórmula química del esmalte de un diente identificando los elementos químicos que la componen, y calcular el número de átomos de calcio de un diente. 


\section{Bloque C: La prevención de la caries}

6.

La prevención

Identificar en un anuncio publicitario del Ministerio de Sanidad español (Ministerio de Sanidad, 2008) los aspectos básicos para prevenir la caries: hacer revisiones al dentista, cepillado de dientes y no abusar de alimentos azucarados.

Se pretende que los alumnos conozcan los factores clave para la prevención de la caries, a la vez que aprenden a identificar ideas importantes que aparecen en un formato audiovisual.

\section{Prevenir haciendo revisiones periódicas en el dentista}

Hacer una pequeña simulación del problema donde un estudiante será el paciente y otro el dentista. El dentista debe informar a su paciente y a la clase, a partir de una radiografía dental donde se pueden apreciar dientes con y sin caries, qué le ocurre y cuál es el tratamiento más adecuado.

Se trata de que el estudiante, simulando la práctica profesional de un odontólogo, utilice el lenguaje científico adecuado para explicar cómo se detecta una caries mediante una radiografía dental. Todo ello para hacer consciente al alumno de la necesidad de las revisiones periódicas.

$\mathrm{CC}$

\section{Prevenir cepillándonos los dientes}

Identificar cuáles son los componentes principales de una pasta de dientes a partir de la etiqueta de varios dentífricos, deduciendo las sustancias en común.

Se pretende que el alumno conozca las sustancias químicas más comunes en los dentífricos y sus funciones, para que puedan tomar conciencia de la importancia del cepillado en la prevención.

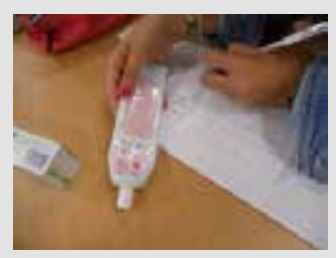

9. Prevenir no abusando de los alimentos azucarados

Buscar en Internet el contenido de azúcar que poseen distintos alimentos azucarados, para estimar la cantidad de azúcar ingerida cada día. Reflexionar sobre si la cantidad de azúcar que suele consumir el alumno se ajusta o no a una dieta equilibrada.

Se pretende, que el estudiante tome conciencia de la relación clara que existe entre consumo de azúcar y desarrollo de caries.

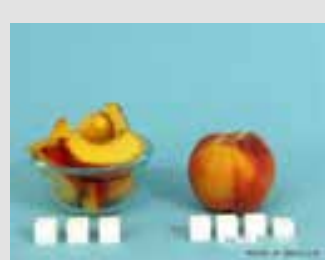

$\mathrm{CC}, \mathrm{CM}$

TICD

AIP

\section{Bloque D: ¿Qué debo hacer si la prevención falla?}

10.

Explicar con sus palabras qué es un empaste y qué materiales utiliza el dentista en este tratamiento.

Se pretende que el alumno reflexione, utilizando el caso del mercurioen los empastes, sobre los posibles

efectos negativos para la salud del uso de determinados materiales. 


\section{Fase de aplicación de conocimientos}

\section{Bloque E: Dando a conocer el problema}

11.

Elaborar un tríptico informativo sobre el problema para distribuirlo en el instituto mostrando en el mismo los principales aspectos de la unidad.

Se pretende que el estudiante ejercite su capacidad de síntesis y de comunicación de lo que ha aprendido.

Realizar un trabajo final sobre la influencia del consumo de alcohol/ tabaco/otras drogas en la aparición de caries basándose en diferentes fuentes de Internet. El trabajo se debe realizar en papel y mediante una exposición oral en clase, en la que los alumnos deben justificar la relación

12. existente basándose en datos.

Se pretende que el estudiante, trabajando en pequeño grupo, aplique lo aprendido sobre las fuentes de información en Internet (Franco, España y Blanco, 2014) y sobre la caries para dar una respuesta fundamentada a una posible relación entre un tipo concreto de droga y la aparición de caries.

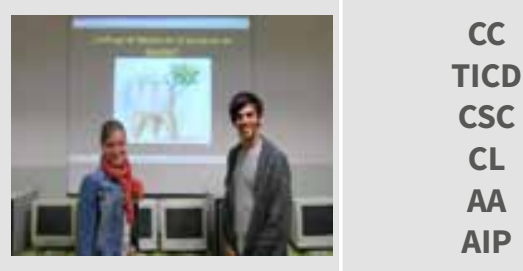

\section{Fase de síntesis, recapitulación y evaluación}

13. Los alumnos resuelven una prueba escrita y responden a un cuestionario de valoración de la experiencia.

Tabla 2. Secuencia didáctica de la unidad sobre salud e higiene bucal

\section{Puesta en práctica}

La unidad didáctica se ha implementado en el instituto de educación secundaria Juan Ramón Jiménez de Málaga (España) con un total de 34 estudiantes de 15-16 años pertenecientes a tres grupos diferentes, durante los cursos 2011-12, 2012-13 y 2013-14. El rendimiento académico de dichos alumnos era medio-alto y pretendían estudiar en el futuro opciones de ciencias, según manifestaban en sus preferencias la mayoría de ellos.

La unidad se desarrolló en 10 sesiones de una hora de duración cada una, a razón de tres semanales. Las sesiones tuvieron lugar en el aula de laboratorio donde los alumnos podían trabajar en pequeños grupos y disponer de ordenadores con acceso a Internet.

Esta unidad se presentó a los estudiantes en dos formatos complementarios. Por un lado, como unidad didáctica en formato web (López, Blanco y Haro, 2011) desde donde se podía acceder a todas las actividades y recursos disponiblesy, por otro, a través de un cuaderno de trabajo impreso. Dicho cuaderno presentaba todas las tareas a realizar e incluía un espacio para que el estudiante pudiese cumplimentar sus respuestas y hacer anotaciones. La unidad didáctica en formato web recogía las mismas tareasy además incluía enlaces a las páginas web, vídeos o imágenes necesarios para realizar las actividades con éxito.

\section{Evaluación de las competencias}

Los instrumentos empleados para evaluar el desarrollo de las competencias básicas fueron las producciones escritas y orales de los estudiantes, grabaciones en vídeo de algunas de las sesiones, entrevistas individuales a alumnos, el diario del profesor investigador, una prueba escrita y registros del interés mostrado por los alumnos. El cuaderno de trabajo del estudiante debía incluir todas las actividades realizadas, tanto individuales como grupales. La prueba escrita se diseñó considerando el tipo de tareas desarrolladas en el aula.

La evaluación tuvo en cuenta el grado de desarrollo por parte del alumnado de las competencias, según los objetivos de la Tabla 1. A continuación se comentan los criterios e instrumentos empleados para evaluar las distintas competencias básicas.

Para la evaluación del grado de desarrollo de la competencia científica por parte del alumnado, resultó especialmente útil la prueba escrita, que los estudiantes resolvieron a modo de pre-test y post-test en dos momentos de la implementación de la unidad, antes y después de la misma. El análisis de las respuestas del alumnado mostró que tras la implementación los estudiantes utilizaban explicaciones más adecuadas al tema en cuestión. Así, a modo de ejemplo, se presentan en la Tabla 3 algunas de las respuestas dadas por los alumnos al inicio y al final de la unidad para una de las cuestiones incluida en la prueba: “qué significa para ti picarse un diente?”. 


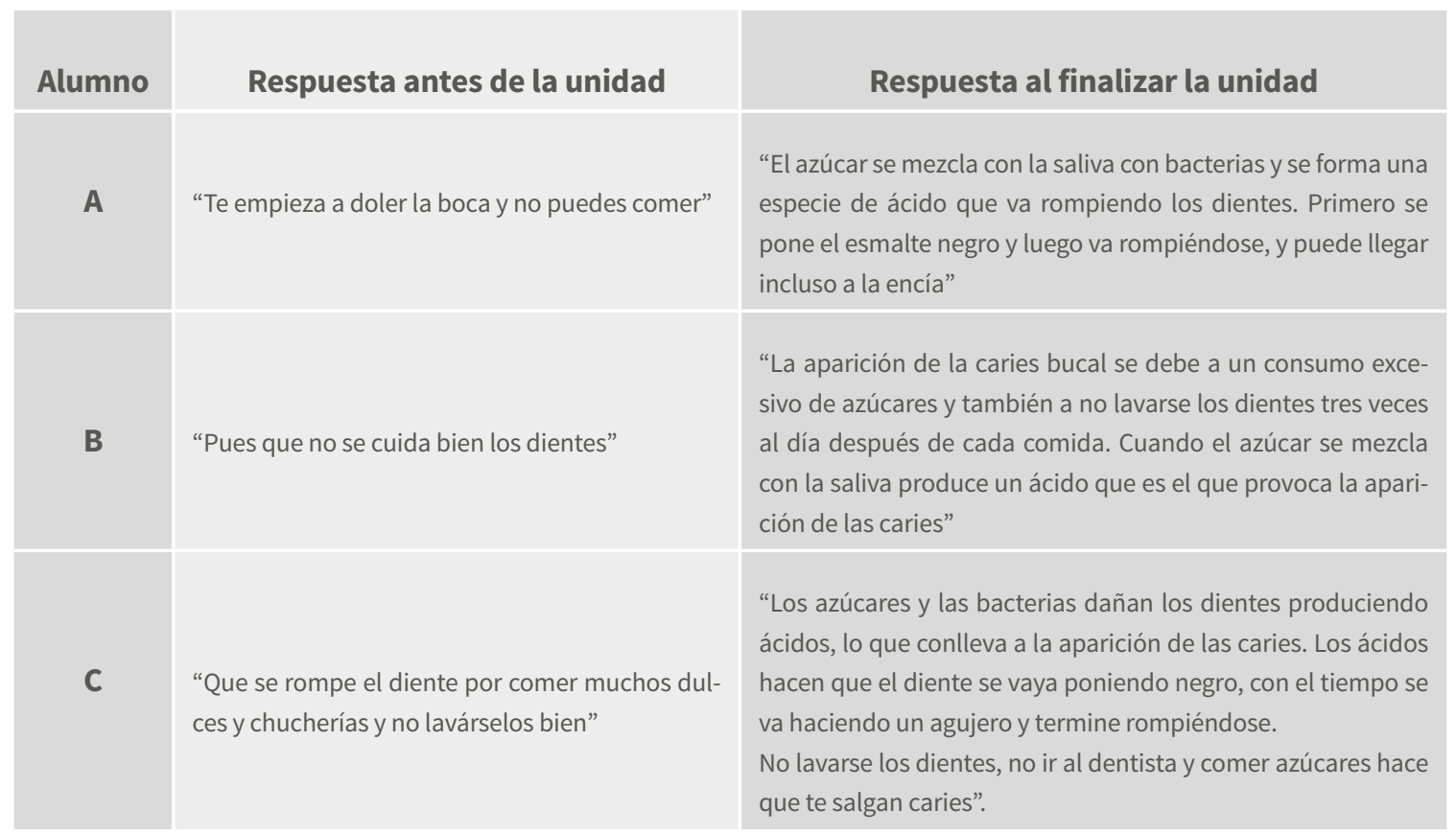

Tabla 3. Algunas respuestas dadas por los estudiantes antes y después de la puesta en práctica para la cuestión ¿qué significa para ti picarse un diente?

Como se puede apreciar en la Tabla 3, estos resultados ponen de manifiesto una evolución en el desarrollo de la competencia científica en estos alumnos ya que las respuestas dadas pasan de ser simples, descriptivas y con el uso de una terminología más cotidiana al comienzo de la unidad, a contener explicaciones más ricas y completas, y empleando términos científicos tras la implementación, a pesar de que en algunos casos aún persisten errores conceptuales. Estos resultados obtenidos en la cuestión presentada y en otras más, muestran que la mayoría del alumnado avanzó en su capacidad de explicar diferentes aspectos relacionados con la salud bucal utilizando conocimientos y argumentos científicos (objetivo 1 de la unidad didáctica).

En la evaluación de la competencia lingüística se tuvo en cuenta el uso adecuado del vocabulario científico, su participación en los debates, la capacidad de elaborar resúmenes e informes, así como la habilidad para obtener, seleccionar e integrar distinto tipo de información.

Por su parte, la competencia matemática se evaluó a través del significado que daba cada estudiante a los resultados de los cálculos numéricos realizados dentro del problema de la caries.

Algunos criterios para evaluar la competencia digital fueron el tratamiento que los estudiantes dieron a la información y su capacidad para discernir información fiabley de calidad de aquella que no lo es. Entre estos criterios se utilizaron: a) la identificación del autor de la web, valorándose más los contenidos realizados por responsables colectivos-centros de investigación o universidades-que por un individuo, y dentro de estos últimos los de mayor cualificación profesional; b) la inteligibilidad del mensaje, valorándose positivamente redacciones adecuadas tanto a nivel ortográfico como gramatical, y la distinción entre información y opinión; c) la independencia del mensaje, donde se valora especialmente la separación de la información de posibles mensajes publicitarios contenidos en la web, entre otros (Franco, España y Blanco, 2014).

En la evaluación de la competencia social y ciudadana se consideró la forma de trabajar el alumno en grupo, así como la responsabilidad que había tenido en el mismo y el respeto a sus compañeros.

La competencia cultural y artística se evaluó a partir del diseño de los trípticos elaborados por los estudiantes para dar a conocer el problema a sus compañeros.

La capacidad de organización del trabajo o la aplicación de lo aprendido a otros contextos fueron algunos de los criterios aplicados para evaluar la competencia aprender a aprender.

La competencia autonomía e iniciativa personal se evaluó a través de registros del grado de autonomía de los estudiantes en su trabajo, su implicación en las tareas y su creatividad. 
Finalmente, para conocer la valoración de la experiencia por parte de los estudiantes, se pasó un cuestionario. De su análisis se concluye que el $72 \%$ consideró que se había trabajado en clase de una forma innovadora, al $86 \%$ le parecieron interesantes los contenidos abordados, el 86\% se sintió implicado y el $72 \%$ de los alumnos afirmó que había aprendido mucho sobre el tema.

\section{Reflexiones finales}

El trabajo aquí presentado se inserta en el contexto del diseño y evaluación de una nueva unidad didáctica, en el que se ha puesto el énfasis en obtener la mayor adecuación posible de la unidad didáctica a los objetivos pretendidos. Se pretende, mediante ciclos de diseño, implementación y revisión, propios de las investigaciones basadas en el diseño (Rainulo y Donolo, 2010) conseguir que la unidad didáctica ofrezca buenas oportunidades a los estudiantes para desarrollar sus competencias básicas tratando cuestiones relacionadas con la salud e higiene bucodental.

En este sentido, los cambios realizados en la unidad didáctica en los sucesivos cursos, productos de la evaluación realizada tras cada implementación, así como la positiva acogida de la misma por parte de los estudiantes sugiere que se trata, de partida, de una buena herramienta didáctica para tratar de forma integrada la salud bucodental y propiciar el desarrollo de competencias básicas.

Por otro lado, somos conscientes de que el desarrollo de competencias por parte de los alumnos depende de muchos factores, pero sobre todo de buenas prácticas docentes, y de tiempo. No es algo que se pueda conseguir con la enseñanza de una única unidad didáctica y un pequeño número de clases. Por esta razón, esta unidad se trabaja en conjunto con otras basadas en contextos y problemas de la vida diaria, y diseñadas todas ellas en el seno del proyecto de investigación citado con anterioridad (Blanco, España y González, 2010) con el objetivo de desarrollar competencias en los estudiantes de secundaria.

En líneas generales, podemos considerar que la unidad desarrollada parece haber contribuido a interesar a los estudiantes de 15-16 años en aspectos relativos a la higiene y la salud bucodental y a concienciarlos en que constituye un problema de la vida diaria al que deben prestar atención. También parece haber contribuido al desarrollo de las competencias básicas de los estudiantes en una clase de biología, a la vez que se interesaban por contenidos científicos. Se valora especialmente la motivación detectada y la implicación de los alumnos en la mayoría de las tareas propuestas.

\section{Referencias bibliográficas}

Blanco, A., España, E. \& González, F.J. (2010). Un proyecto de investigación para el fomento de la competencia científica en la educación obligatoria, en Quesada A. \& Abril, A. (eds.): Actas de los XXIV Encuentros de Didáctica de las Ciencias Experimentales, pp. 729735. Jaén (España): Universidad de Jaén.

Blanco, A., España, E., González, F.J. \& Franco, A.J. (2015). Key Aspects of Scientific Competence for Citizenship: A Delphi study of the Expert Community in Spain. Journal of Research in Science Teaching, 52(2), 164-198.

Blanco, A., España, E.\& Rodríguez, F. (2012). Contexto y enseñanza de la competencia científica. Alambique, Didáctica de las Ciencias Experimentales, 70, 9-18.

Bravo, M., Casals, E., Cortés, F. \& Llodra, J. (2006). Encuesta de Salud Oral en España 2005. RCOE, Revista del Ilustre Consejo General de Colegios de Odontólogos y Estomatólogos de España, 11(4), 409-456.

España, E., Blanco, A. \& Rueda, J.A. (2012). Identificación de problemas de la vida diaria como contextos para el desarrollo de la competencia científica. En Membiela, P.; Casado, N. y Cebreiros, M.I. (eds.). Experiencias de investigación e innovación en la enseñanza de las ciencias. Ourense: Educación Editora, pp. 169-173.

Franco, A.J., España, E. \& Blanco, A. (2014). Uso de Internet para analizar las relaciones entre drogas y salud bucodental. Una experiencia en $4^{\circ}$ de E.S.O. En Soriano, E.; González, A.J. y Cala, V.C. (eds.): Retos actuales de educación y salud transcultural [1], pp. 54.1-54.8. Almería (España): Universidad de Almería.

Fornás, R. (2003). Criterios para evaluar la calidad y fiabilidad de los contenidos en Internet. Rev. Esp. Doc. Cient., 26(1), 75-80.

López, J.; Blanco, A. \& Haro, G. (2011). Ahorra energía: ¡Tú puedes! Una unidad didáctica web para el desarrollo de la competencia científica y la competencia digital. Buenas prácticas con TIC para la investigación y la docencia. Málaga (España): Universidad de Málaga, 14-16 diciembre.

Ministerio de Educación y Ciencia (2007). Real Decreto 1631/2006, de 29 de Diciembre (BOE de 5 de Enero de 2007) por el que se establecen las enseñanzas mínimas correspondientes a la Educación Secundaria Obligatoria. 
Ministerio de Sanidad (2008). Spot de la campaña "Que molen tus muelas". Disponible on-line en: https:// www.youtube.com/watch?v=kGidjOfhC70 (Acceso: 16/11/2014).

OCDE (2006). PISA 2006. Marco de la evaluación, conocimientos y habilidades en ciencias, matemáticas y lectura. Madrid (España): Santillana.

Perrenoud, P. (2012). Cuando la escuela pretende preparar para la vida. ¿Desarrollar competencias o enseñar otros saberes? Barcelona (España): Graó.

Pro, A. \& Saura, O. (2007). La planificación: un proceso para la formación, la innovación y la investigación. Alambique, Didáctica de las Ciencias Experimentales, 52, 39-55.

Rianudo, M. y Donolo, D. (2010). Estudios de diseño. Una perspectiva prometedora en la investigación educativa. Revista de Educación a Distancia, 22, 1-29.

Ramos, M.P. (2010). Estilos de vida y salud en la adolescencia. Tesis Doctoral. Sevilla (España): Universidad de Sevilla. 